\title{
Role of extension professionals in determining marketing behaviour of the farmers indulged in Horticulture sector in Indian context: A review
}

\section{Shubhangi Kanwal}

Department of Agricultural Communication, College of Agriculture, Govind Ballabh Pant University of Agriculture and Technology, Pantnagar, U.S. Nagar- 263145 (Uttarakhand), India

\section{S.K. Kashyap*}

Department of Agricultural Communication, College of Agriculture, Govind Ballabh Pant University of Agriculture and Technology, Pantnagar, U.S. Nagar- 263145 (Uttarakhand), India

*Corresponding author. E-mail: kashyapsk@gmail.com

\begin{abstract}
The companionship of advanced technology and easy outlay for the primary products have always been a prime focus to boost economy of the nation. Although, India has gone through a major transformation from being food deficient to now the leading producer and exporter of many agricultural commodities. The socio-economic condition of the farmer has not witnessed a noticeable change. The root cause identified by the researchers being the existence of long supply chains, lack of awareness, inadequate infrastructural facilities, etc. Researches analyzing the marketing behaviour of the farmers may help in identifying the constraints faced by the farmers in marketing their produce for optimum returns. Also, results may help to purview the factors contributing to better marketing by analyzing the varied behaviour of the farmers. Proper analysis, devising the effective strategy and its implementation require well-equipped extension professionals with upgraded skills and futuristic vision.
\end{abstract}

Keywords: Extension professionals, Farmers, Futuristic vision, Revamp

\section{Article Info}

DOI:10.31018/jans.v11i2.2084

Received: April 28, 2019

Revised: May 30, 2019

Accepted: June 3, 2019

\section{How to Cite}

Kanwal, S. and Kashyap, S.K. (2019). Role of extension professionals in determining marketing behaviour of the farmers indulged in Horticulture sector in Indian context: A review. Journal of Applied and Natural Science, 11 (2): 450 - 454 https:// doi.org/10.31018/ jans.v11i2.2084

\section{INTRODUCTION}

Agriculture is different from other industries as it deals with products that are perishable, possess demand and price inelasticity and plays a significant role in economic development of the nation. Increasing export and processing facilities accompanied by technological advancement has facilitated the roots of commercialization to penetrate deeper into the agriculture sector. Pratap (2011) in a study indicated that the food and economic security of the farmers can be enhanced considering the steep inclinations toward rapid expansion of horticultural crops. Hence, agricultural marketing has a special role in handling high-value horticulture products which will help in increasing farmers' income. According to the National Commission on Agriculture (XII Report, 1976), "Agricultural marketing is a process which starts with a decision to produce a saleable farm commodity, and it involves all the aspects of market structure or system, both functional and institutional, based on technical and economic considerations, and includes pre- and post-harvest operations, assembling, grading, storage, transportation and distribu- tion". Therefore, major problem lies in the performance of marketing functions (packaging, transport, grading, standardization, quality control, storage, processing, market information etc.) by the stakeholders involved in the supply chain of high-value perishable horticultural commodities. Since, the efficient marketing system reduces costs and benefits all the sections of the society. The objective of all the stakeholders must be in knowledge so that problems emerging from the conflicting objectives must be reconciled (Acharya, 2015). Therefore, the preference of stakeholders needs special attention to understand and transform framework under which horticultural products are marketed. This can be assessed by careful analysis of the farmers' behaviour towards marketing, which now has added dimensions as marketing is not limited to when, where and whom to sell; rather, it now also encompasses decision relating what to produce, which variety to produce, how to prepare product for marketing and up to what extent so that it fetches optimum value to the farmer. Therefore, extension teams need to define their area of support and agents need to acquire the right set of 
skills in a particular area, be that input supply, production, post-harvest, marketing, nutrition, gender etc. These core sets of skills change with time and as research identify new needs and clients make investment decisions (Davis, 2015).

Behavioural studies of key stakeholders primarily the producers can help in defining the emerging roles and thereby, help in identifying necessary competencies to be taken up by the extension system to uplift the condition of the farming community. According to the theory of planned behaviour, the behaviour of an individual is a cumulative outcome of three kinds of considerations: behavioural beliefs, normative beliefs and control beliefs (Ajzen, 1991). This theory was derived from the theory of reasoned action (Fishbein and Ajzen, 1975), which assumed that most human social behaviour depends upon the individual will and, hence, can be predicted from intentions alone. To lodge the non-volitional elements inherent, at least potentially, in all behaviours, the concept of perceived behavioural control was added to the theory of planned behaviour (Azen, 2002). Therefore, one's behaviour can be considered as cumulative outcome of individual differences, economic factors, social factors, environmental factors and psychological factors. Similarly, the marketing behaviour of farmers can be conceptualized as the way in which the farmer conducts marketing functions to market his/ her produce. The marketing functions include transport, packaging, grading, quality control, processing and value addition, price determination, financing for marketing, market information and risk-bearing ability. Considering the process involved in performing these marketing functions marketing behaviour is the outcome of planning influenced by the economic, social, psychological and environmental factors which are reflected in the actions of the farmer.

Determinants of marketing behaviour: Marketing behaviour is the way in which an individual conducts marketing functions and is capable to reason his actions and decisions. The results of the studies accessing marketing behaviour revealed that reasons behind the actions are equally important to assess the marketing behaviour of the farmers. Responses related to time, place and channel of sale along with the reason for that particular response on the basis of priority were analyzed. Financial urgency, perishable nature of produce as a major reason for selling the produce immediately after harvest; ease of assess w.r.t. time and place along with better price as the major reason for selling the produce to wholesalers through commission agents (Santoshkumar, 2008, Chandrashekhar, 2007). There exists a positive and significant relationship of marketing behaviour with information sources, utilization pattern, infrastructure facilities and risk orientation (Devde, 2017). Further a comparative study on marketing behaviour indicated that nature of produce affects the marketing behaviour of the growers in terms of place, time and channel of selling the produce (Jahangirali, 2014).

Gangadhar, (2009) conceptualized marketing behaviour as the overall effect of various components taken for study i.e., planning orientation, production orientation, marketing information sources utilization, marketing orientation, decision -making ability, risk-taking ability, innovativeness, mode of transport, place of sale, terms and conditions of the sale. The study revealed that majority of the respondents had medium level of marketing behaviour with majority of the components with medium values. It was also found that farmers sell their produce to marketing yards and preferred immediate payment agreements. Shekhar, (2009) studied marketing behaviour of farmers by assessing the different components such as planning orientation, information source utilization, value addition, grading of the produce, mode of packing, mode of transport, distance of the market, place of sale, storage facilities, quality orientation, terms and conditions for sale and export orientation. The study revealed that farmers had medium level of overall marketing behaviour which is consistent with the findings of (Gangadhar, 2009). Low information source utilization and export orientation were reported by Shekhar, (2009) with medium levels of quality orientation and value addition. Study also revealed the persistent use of gunny bags for storage, selling the produce without grading, auction as the preferred mode of sale and prior payments as the preferred mode of payment by the farmers. Kumar et al., (2018) in a study "Marketing Behaviour of Vegetable Growers in Uttarakhand hills" inferred that 95 per cent of the respondents sold the entire produce immediately after harvest due to perishability of the produce and lack of storage. Most of the respondents $(85.83 \%)$ sold their full amount of marketable surplus to the retailers/merchants/ commission agents available at village. Grading is the best practice for higher market price and majority of the respondents $(73.33 \%)$ followed it. Johnson and Manoharan, (2009) in a study revealed that majority of the produce is marketed without value addition and highlighted the key role of middlemen in reducing the dividends/ margins for the farmers. Raina et al, (2011) also suggested the lack of proper infrastructure facilities hinders value addition and lack of proper price policies facilitates the addition of intermediaries in marketing chain. Murthy et al., (2007) reported progress in pricing efficiency in terms of lower price-spread, higher efficiency index, increased producers' share and lower consumers' price. Ladaniya and Vinod, (2004) in a study on "Marketing of banana in selected districts of India" reported that the share of the banana producer in the price paid by 
the consumer was nearly $28 \%$ in two major channels in which farmers sold the produce to buyers of distant market through cooperative societies and commission agents. A similar study conducted in peri-urban res of Uttarakhand, Uttar Pradesh and Haryana reported that net returns to farmers through value addition and shorter marketing channels are significantly higher (Gills, 2015). Pandey et al,. (2011) in a study in Kumaon region of Uttarakhand revealed that the producers are getting only nine per cent of the consumer's price in marketing the fruits.

The studies on marketing behaviour revealed that the nature of produce, time, place and form in which produce is marketed are the key determinants of marketing behaviour. Planning orientation, information source utilization, value addition, grading of the produce, mode of packing, mode of transport, distance of the market, place of sale, storage facilities, quality orientation, terms and conditions for sale and export orientation and risk orientation of the farmer towards production and marketing were also reported as the prime factors affecting marketing behaviour. Besides determinants and influencing factors studies also reported the constraints faced by the farmers in marketing the produce. Constraints faced also reflects the injustice played by the middlemen in reducing the producer share in consumer's price. Studies also identified the changing trend of first step marketing i.e., increasing farmer preference in value addition and shorter marketing channel for increased margins. Hence, it is evident that with proper assistance farmer is ready for bringing positive change through self-help.

Changing roles of extension professionals: India being a developing agrarian nation has been through a transitional phase since independence, from securing food security to commercializing the agriculture sector for attaining sustainable development. The transitional phase towards development is always accompanied by the extension services that have always played an irreplaceable role in advancing and mainstreaming agriculture which is intangible with the goal of rural development. Role of agriculture extension has been widely appreciated around the world in developing agriculture. Tracing the success of either agriculture or rural development projects in India, agriculture extension has proven its worth. It has actively contributed to the success and evolution of many development programmes like CDP (1952), Intensive Agricultural District Program (1960), Intensive Agricultural Area Program (1964), High Yielding Variety Program (1966), T and V system (1974), DWCRA (1972), NRLM (2011), SETU Scheme (2015) etc. It also shared an appreciable credit in the success of Green Revolution which proved to be a major hike in agriculture production making in India self-sufficient in food grains. Van den Ban and Hawkin (1988), defined extension as involving the conscious use of communication of information to help people form sound opinions and make good decisions. Extension as a science deals with the creation, transmission and application of knowledge designed to bring about planned changes in the behavioural complex of people with a view to helping them live a better life through learning new ways of improving their vocation, enterprise and institution (Maunder, 1972).

Production and marketing are the major concern of almost all rural development programmes based on agriculture. As agricultural extension work as a system for improving conventional farming practices of the farming community by diffusing latest farming methods and ideas to them. Therefore, advances in agriculture and technology can reach the target audience when coupled with extension services (Abbas et al., 2008).

Rural markets are primary point of contact of the farmers with the market economy, both for buying and selling. Farmers are being exploited by the traders and commission agents to their advantage due to existence of high price differentials between wholesale and rural markets. Therefore, it is vital for the rural markets to make wholesale markets as their price discovery point, taking transport and other costs into consideration (National Institute of Agricultural Extension Management). In a country like India, where the majority of its population still resides in villages and depends on agriculture, timely market intelligence about the agricultural commodities is of extreme significance. As farmers are becoming market-oriented and exhibit medium marketing behaviour, extension professionals need to undertake advisory role not only limited to how to excel the production but also how to market the produce profitably. This concept of expanding the horizon of agriculture extension towards agriculture produce marketing has emerged as marketled extension which is defined as "The market ward orientation of agriculture through extension includes agriculture and economics is the perfect blend for reaching at the doorsteps of farming community with the help of appropriate technology" (Kaleel, 2007).

Extension personnel act as a driver to change by planning, implementing and evaluating the strategic coupling of advances as per need of the target audience. Therefore, extension personnel need to be updated to keep a better watch over the need, trend and advances. Change in agriculture is essential for national progress to occur in developing countries since, subsistence or traditional agriculture still dominates their economy. The change is needed not only to increase production but to liberate households from poverty as well. For bringing about this change responsibility rests on the shoulders of extension workers (Anaeto et al. 2012). The success of most of the production-oriented 
development programmes is determined by value addition and efficient marketing. Existing dependency on external agencies and poor market planning by the farmers often leads to failure of most of the rural development projects dealing with farming sector, where the profit margins are under severe pressure. (Hegde, 2012). To minimize the farmers' distress, arranging the education and awareness program for the rural farmers is essential, to improve their knowledge in improving agroproduce and its marketing process along with the implementation of fast track infrastructural facilities under rural development projects for exploiting the place and time utility. Also, creation of direct contact network between the farmers and customers that would help in reduction of involvement functionaries and also to reduce the unnecessary brokerage or commission to the functionaries is also required Kiruthiga et al., (2015).

Since, marketing is different from mere selling the produce in the market its assessment by the professionals to trace the changing trend, behaviour of stakeholders and constraints in marketing the high-value perishable agriculture commodities is required. It must be accessed by integrating the widely accepted economic approaches like commodity approach, institutional approach, functional approach and management approach with extension principles and planning. Marketing extension would help in enhancing the marketability of the produce by way of disseminating post-harvest management technologies viz, product handling, cleaning, drying, grading, packaging, storage, processing, value addition, transportation etc. along with the adequate market information. As marketing efficiency is inversely proportional to the marketing losses Murthy et.al., (2007) reported the need for highly specialized extension system that focuses on increasing marketing efficiency. Increased marketing efficiency ultimately increase the producers share in consumer rupees which is being reported marginal due to existing intermediaries in the marketing channel. Gandhi and Namboodiri, (2004) stated that there is substantial scope for improving the marketing efficiency by improving the market information system. for which latest and extensive market information available can be utilized by all market participants through the use of internet facilities and other means of communication. Therefore, relevancy of the extension system which would broaden its client and technological changes affecting the operation of the enterprises linked in the value chain of agriculture remains to its mandate, as well as demands of its client and could sustain and expand its operation Hassanullah, (2006).

Towards the changing needs: Researches around the globe suggest the changing roles of extension professionals and the need for an upgrade in their skillset. Terblanché, (2008) suggest- ed extension needs for vision focused on the future which demands professional services by the trained and upskilled professionals. Houser et al,. (2018) studied the low use of extension as an information source for farm management decisions and make recommendations. Conservative recommendations, declines in public funding, and the perception of "cutting-edge" private sector information were reported as key factors for its low use. They further recommended that changes to extension at system and ground levels could potentially increase its use among farmers. Whitaker et al., (2018) suggested the need to transmit internet-based media strategies of marketing professionals to Extension professionals' need, to enhance Extension professionals' success in using Internet-based media. As extension audience are changing despite being rural they are actively engaged in using diverse mass media and internet is gaining wide acceptance in this scenario. Schmieder et al., (2018) proposed the use of data jam model to upskill the extension. It is an evaluation capacity building framework for collaborative, mentorship-based analysis sessions across an institution and across disciplines. Stone, (2006) put forth the use of commercially on-ground agribusiness extension specialists for dissemination of RandD results and to provide input into extension programs. Considering the changing needs, there stands the need to revamp the extension by tracking the changing global trends along with principles and philosophy of extension intact in its approach.

\section{Conclusion}

The agriculture sector in India has witnessed changes over the decades from being subsistence to being market-led. Analyzing the literatures reviewed there lacks the noticeable change in socioeconomic conditions of the prime stakeholder of this sector i.e., farmer. The prime reason for their low economic status being involvement of a large number of intermediaries in the supply chain which engulfs a huge proportion of their share in consumer money was reported by researchers. This problem can be catered by generating awareness and upskilling farmers with the futuristic vision to entrap immense opportunities in the agriculture sector. The seed of futuristic vision can be converted into reality by proper guidance and assistance by the revamped extension run by highly competent and skilled extension professionals.

\section{REFERENCES}

1. Abbas, M., Lodhi, T. T. Bashir, A. and Mehmood, M.A. (2008). Dissemination of wheat production technologies and interface of outreach efforts with farmers. J.Agric. Res., 46(1): 99-108

2. Acharya, S.S. and Agarwal, N.L. (2015). Agricultural Marketing in India, New Delhi: Oxford and IBH Publishing Co. 
3. Ajzen, I. (1991). The theory of planned behavior. Organizational behavior and human decision processes, 50(2):179-211.

4. Anaeto, F.C. et. al. (2012). The role of Extension Officers and Extension Services in the Development of Agriculture in Nigeria. Wudpecker Journal of Agricultural Research, 1(6): $180-185$.

5. Chandrashekhar, S. K. (2007). Analysis of Onion Production and Marketing Behaviour of Farmers in Gadag district, Karnataka. Thesis, Masters. University of Agricultural Sciences, Dharwad, India.

6. Davis, K. (2015). The new extensionist: Core competencies for individuals. GFRAS Brief, 3.

7. Devde, P. U. (2017). Marketing behaviour of vegetable growers. Thesis, Masters. Vasantrao Naik Marathwada Krishi Vidyapeeth, Parbhani, India.

8. Fishbein, M., and Ajzen, I. (1975). Belief, attitude, intention, and behavior: An introduction to theory and research. Reading, MA: Addison-Wesley.

9. Gangadhar, J. (2009). Marketing Behaviour of Cotton Farmers in Warangal District of Andhra Pradesh. Thesis, Masters. Acharya N.G.Ranga Agricultural University, Hyderabad, India.

10.Gandhi, V.P. and Namboodiri, N.V. (2004). Marketing of Fruits and Vegetables in India: A Study Covering the Ahmedabad, Chennai and Kolkata Markets. Working paper: IIM A. issue date: 22/7/2010.

11.Gills, R. (2015). Post-Harvest Decision Making Pattern and Marketing Behaviour of Peri Urban Farmers. Thesis, PHD. Indian Agricultural Research Institute, New Delhi.

12. Hassanullah, M. (2006). Commercialization Of Agriculture And The Role Of Agricultural Extension Services In Asian Nations. Agricultural Extension, 175.

13. Hegde, N. G. (2010). Development of value chain for sustainable agriculture. Financing Agriculture, 42(7): 26-28.

14. Houser, M. et.al. (2018). Strategies for Enhancing University Extension's Role as an Agricultural Information Source. Journal of Extension, 56 (6). Feature (6FEA5). Retrieved May 01, 2019 from http:// www.joe.org/joe/2018october/a5.php.

15.http://www.manage.gov.in/studymaterial/scm-E.pdf. Supply chain management in agriculture reading material.02-04-2019. (National Institute of Agricultural Extension Management)

16.National Commission on Agriculture Report. (1976).Crop production and sericulture and apiculture. Government of India press, New Delhi.

17.Jahangirali, M. (2014). Comparative Analysis of Marketing Behaviour of Wheat and Tomato Growers in Dharwad District of Karnataka. Thesis, Masters. University of Agricultural Sciences, Dharwad, India.

18.Johnson, B and Manoharan, M. (2009). Marketing Behaviour of Cashew Farmers. Indian Research Journal of Extension Education, 9 (1):6-10.

19.Kaleel, F. M. H., Krishnankutty, J. and Babu, K. S. (2007). Market-led extension dimensions and tools. Agrotech Publishing Academy, Udaipur, India.

20.Kiruthiga, K., Karthi, R. and Daisy, B. A. (2015). Agricultural marketing: An overview. International Journal of Scientific and Research Publications, 5(4):1-3.

21.Kumar, S., Roy, M. and Mukherjee, A. (2018). Marketing Behaviour of Vegetable Growers in Uttarakhand hills. Journal of Community Mobilization and Sustainable Development, 13(1): 68-74.

22.Ladaniya, M.S. and Vinod, W. (2001). Marketing pattern of 'Mosambi' sweet orange in selected districts of Maharashtra. Indian journal of Agricultural Marketing, 17(1): 52-62.

23.Maunder, A. (1972). Agricultural Extension: A Reference Manual. Module 4. Behaviour Modification. 2000. Regional Training Seminar on Guidance and Counselling: UNESCO, Uganda.

24.Murthy, S., Gajanana, T.M., Sudha, M. and Dakshinamoorthy, V. (2007). Marketing Losses and Their Impact on Marketing Margins: A Case Study of Banana in Karnataka. Agricultural Economics Research Review, 20: 47-60.

25.Pandey, D., Kumar, A., and Singh, R. (2011). Marketing Of Sweet Orange (Malta) In Kumaon Region Of Uttarakhand. Journal of Recent Advances in Applied Sciences, 26.

26.Pratap, Tej. (2011). Hill Agriculture: Challenges and Opportunities. Ind. Jn. of Agri.Economics. 66(1).

27.Raina, V., Nain, M.S., Hansra, B.S. and Singh, D. (2011). Marketing Behaviour and Information Sources Utilization Pattern of Flower Growers. Journal of Community Mobilization and Sustainable Development, 6(2): 180-184

28.Santoshkumar, S.P. (2008). Marketing Behaviour, Information Source Consultancy Pattern and Problems of Vegetable Growers in Bijapur District of Karnataka. Thesis, Masters. University of Agricultural Sciences, Dharwad, India.

29.Schmieder, C., Cadwell, K.E.H. and Bechtol, E. (2018). Readying Extension for the Systematic Analysis of Large Qualitative Data Sets. Journal of Extension. 56(6). Feature (6FEA2). Retrieved on May 01, 2019 from http://www.joe.org/joe/2018october/ a2.php.

30.Shekhar, B.R. (2009). Study on Marketing Behaviour of Chilli Growers in Guntur District Of Andhra Pradesh. Thesis, MSc. Acharya N.G.Ranga Agricultural University, Hyderabad, India

31.Stone, G. (2006). Agribusiness Role in Extension, Education and Training - A Case Study (www.regional.org.au/au/apen/2006/ refereed/6/3093_stonegc.htm)

32. Terblanché, S.E. (2008). Towards an improved agricultural extension service as a key role player in the settlement of new farmers in South Africa. South African Journal of Agricultural Extension, 37(1): 5884.

33. Van den Ban, A. W. and Hawkins, H. S. (1988). Agricultural Extension. Burnt Mill, Harlow.

34.Whitaker, H. Leggette, H.R. and Barbeau, S. (2018). A Marketing Standpoint: What Marketer Can teach Extension Professionals About Internet- Based Media. Journal of Extension, 56(6). Feature (6FEA3). Retrieved May 01, 2019 from http://www.joe.org/ joe/2018october/a3.p 